\title{
Pancreatico-duodenectomy with long segment portal vein resection and reconstruction with left renal vein autologous graft
}

B.K.S. Bulathsinhala, M.S.B. Tillakaratne, M.B. Gunetilleke, R.C. Siriwardana

North Colombo Teaching Hospital, Ragama, Sri Lanka

Key words: Pancreatic cancer; pancreatico-duodenectomy; portal vein resection; portal vein reconstruction; autologous left renal vein graft

\section{Introduction}

Management paradigm of pancreatic cancer (PC) is evolving, yet the only hope of cure is complete resection with negative margin. In minority of cases negative margin during pancreatico-duodenectomy (PD) can be achieved only with portal vein resection (PVR) [1]. Long segment PVR has to be reconstructed using a conduit for which left renal vein autologous graft (LRAG) is a viable option [2,3].

To date there are no reported cases of major PV reconstruction in Sri Lanka. Hence we report our first experience of PVR and reconstruction using LRAG.

\section{Case presentation}

A 47 year old male was investigated for painless obstructive jaundice. Preoperative cross sectional imaging revealed pancreatic head mass with involvement of PV. PD with possible PVR was planned.

Intra operatively hard pancreatic head mass infiltrating about $2 \mathrm{~cm}$ segment of PV at its origin was noted (Figure 1). Following standard dissection pancreas was transected at the neck. Complete uncinate process dissection done and replaced right hepatic artery was appreciated and preserved (Figure 1). Splenic vein was ligated. After fully mobilizing the liver, it was decided that end to end anastomosis of PV was not possible due to longer segment involvement. Considering the normal renal function LRAG was planned.

Kocherization was extended. Left renal vein was exposed slung and traced up to left adrenal vein (Figure 2). Left renal vein was controlled with two clamps and harvested preserving the adrenal vein. $\mathrm{PV}$ reconstruction was completed with LRAG using 5/0 prolene (Figure 3). Postoperative good PV flow was identified. Patient made an uneventful recovery.

Correspondence: Rohan Chaminda Siriwardana

E-mail: rohansiriwardana@yahoo.com

Received: 13-11-2017 Accepted: 11-12-2017

(iD) http://orcid.org/0000-0002-6477-2072

DOI: http://doi.org/10.4038/sljs.v35i4.8437

The Sri Lanka Journal of Surgery 2017; 35(4): 34-35

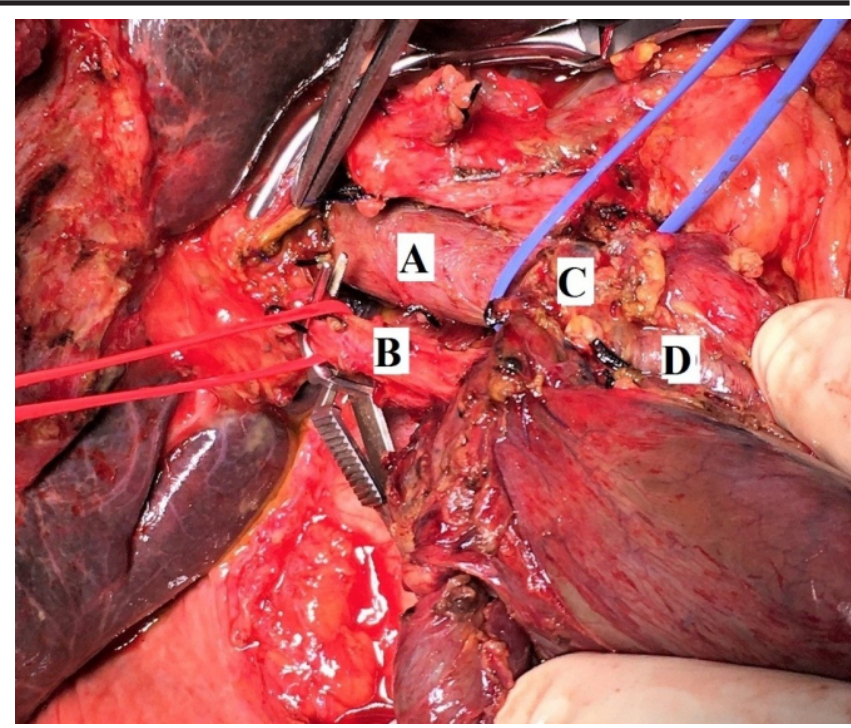

Figure 1. A - Portal vein, B - Replaced right hepatic artery, C - Tumour infiltrating the portal vein, D - Superior mesenteric vein

\section{Discussion}

Surgical resection is the only treatment that offers cure for pancreatic cancer. At times portal vein resection increases the resectability with negative margins, hence chances of cure [1, 4]. First reported case of major venous resection by Moore in 1951. However PVR are exceptional even in high volume hepatobiliary centres [3]. Many studies including a recent meta-analysis proved PVR has no added morbidity and mortality $[1,4,5,6]$.

There are many options for PV reconstruction. Apart from cadaveric grafts, other options such as autologous jugular, left renal, femoral and external iliac veins grafts and synthetic grafts are reportedly used [2, 3]. By preserving the adrenal vein LRAG can be successfully used without remarkable renal dysfunctions [2].

Careful case selection and ability of major venous reconstruction should be the goal in units that treat PC more frequently. 


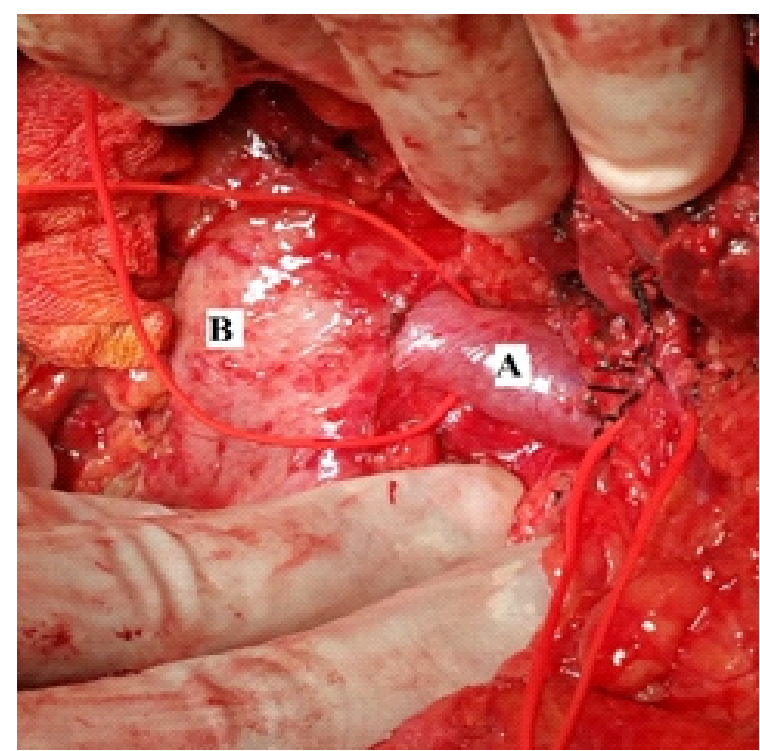

Figure 2. A - Left renal vein, B - IVC

\section{References}

1. Machado MCC, Figueira ERR, Machado MAC, Jukemura J, Cunha JEM, Perini M V., et al. Portal vein resection: A modified technique for reconstruction after pancreatico duodenectomy.

J Surg Oncol. 2004;88(1):52-4.

https://doi.org/10.1002/jso.20114

2. Choi SH, Hwang HK, Kang CM, Lee WJ. Potential use of left renal vein graft in pancreaticoduodenectomy combined with long segmental resection of the superior mesenteric-splenicportal vein confluence. J Pancreas. 2011;12(3):234-40.

3. U.M. M, M. U. Which conduit is the best? Internal juguler vein, left renal vein or synthetic grafts after portal vein/SMV resection during pancreaticoduodenectomy [Internet]. Vol. 55, European Surgical Research.2015.p.109. Available from: http:/ovidsp.ovid.com/ovidweb.cgi?T=JS\&PAGE=reference

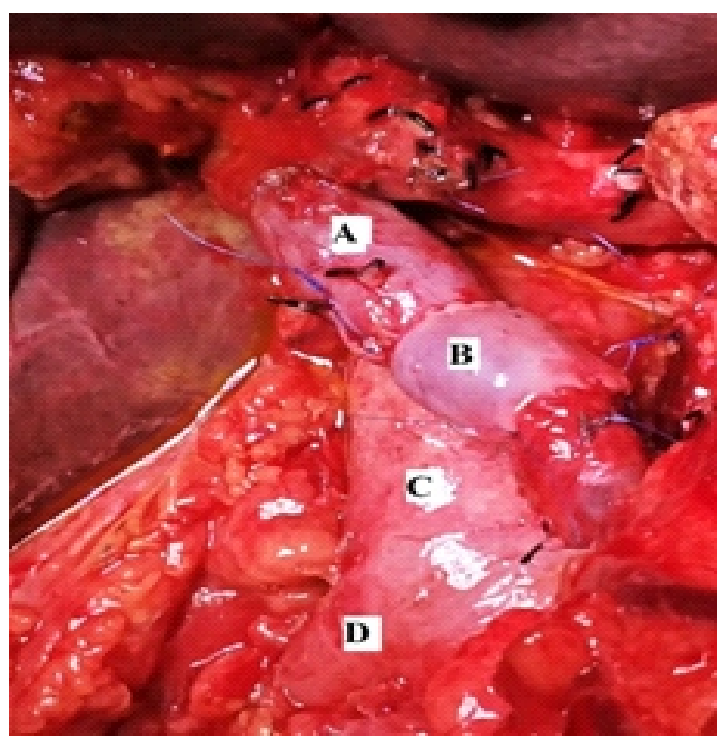

Figure 3. A - Portal vein, B - Autologous left renal vein graft, C - IVC, D - Right renal vein

\section{$\& \mathrm{D}=$ emed $17 \& \mathrm{NEWS}=\mathrm{N} \& \mathrm{AN}=71958350$}

4. Christians KK, Lal A, Pappas S, Quebbeman E, Evans DB. Portal Vein Resection. Vol. 90, Surgical Clinics of North America. 2010. p. 309-22.

https://doi.org/10.1016/j.suc.2009.12.001

5. Amano H, Miura F, Takada T, Sano K. Portal vein resection in pancreaticoduodenectomy (with video). J Hepatobiliary Pancreat Sci.2012;19(2):109-15. https://doi.org/10.1007/s00534-011-0468-4

6. Yu XZ, Li J, Fu DL, Di Y, Yang F, Hao SJ, et al. Benefit from synchronous portal-superior mesenteric vein resection during pancreaticoduodenectomy for cancer: A meta-analysis. Eur $J$ Surg Oncol. 2014;40(4):371-8.

https://doi.org/10.1016/j.ejso.2014.01.010 